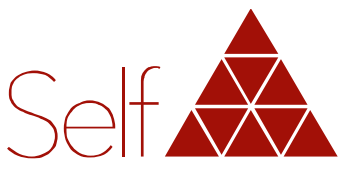

Revista do Instituto Junguiano de Săo Paulo

\title{
As teses que permeiam a conduta de uma pessoa
}

\author{
Alberto Pereira LIMA FILHO
}

São Paulo, SP, Brasil.

\section{Resumo}

Outor apresenta um exercício reflexivo sobre um fenômeno psicológico incidente em muitas vidas: sem que a pessoa necessariamente tenha consciência do conteúdo, uma tese - ou mesmo várias - permeia sua forma de interagir com outras pessoas, seu comportamento em geral, seus posicionamentos, comunicações, decisões, visões de mundo e de si mesma. Há uma articulação teórica e conceitual entre a psicodinâmica desse fenômeno e o conceito de complexo na teoria da psicologia analítica. $\bigcirc$ artigo descreve o fenômeno, faz alusão a suas possíveis gêneses e sinaliza possíveis rotas de superação para as dificuldades dele decorrentes, muitas vezes impeditivas ao desenvolvimento do processo de individuação.

\section{Descritores}

Conflito de interesses: psicologia junguiana, inconsciente, complexo.

O autor declara não haver nenhum interesse profissional ou pessoal que possa gerar conflito de interesses em relação a este manuscrito. 


\title{
The theses that underlie the conduct of a person
}

\begin{abstract}
The author presents an analytical reflection on a psychological phenomenon that occurs in many lives: without the person necessarily being aware of its contents, a thesis - or even several -permeates his or her behavior in general, his or her positions and perspectives, communications, decisions, as well as perceptions of the world and of himself/herself. Their way of interacting with other people, their behavior in general, their stands and perspectives, their communications, their decisions, as well as perceptions of the world and of themselves. There is a theoretical and conceptual articulation between the psychodynamics of this phenomenon and the concept of complex in Analytical Psychology theory. The article describes the phenomenon, alludes to its possible genesis and indicates probable routes to overcome the arising difficulties, often hindering the development of the process of individuation.

\section{Descriptors}

Junguian psychology, unconscious, complex.
\end{abstract}

\section{Las tesis que permean la conducta de una persona}

\section{Resumen}

El autor presenta un ejercicio reflexivo sobre un fenómeno psicológico que ocurre en muchas vidas: sin que la persona necesariamente tenga conciencia del contenido, una tesis - o aún varias- permea(n) su forma de interactuar con otras personas, su comportamiento en general, posicionamientos, comunicaciones, decisiones, visiones del mundo y de sí misma. Hay una articulación teórica y conceptual entre la psicodinámica de este fenómeno y el concepto de complejo en la teoría de la Psicología Analítica. El artículo describe el fenómeno, hace alusión a sus posibles génesis y señala posibles rutas de superación para las dificultades que derivan de él, que muchas veces impiden el desarrollo del proceso de individuación.

\section{Descriptores}

psicología junguiana, incosnciente, complejo. 


\section{Introdução}

Observe-se o conjunto das comunicações de uma pessoa, as coisas a respeito das quais ela fala, principalmente aquelas que ela aborda com horror, com paixão, com convicção, com ênfase, com qualquer tipo de intensidade emocional. Observem-se, em especial, as comunicações e expressões que causam algum estranhamento ao interlocutor, ou the pareçam carregadas de emoção em demasia, despropositadas, incompatíveis com as situações que se apresentam aos seus olhos. Observem-se, ainda, os silêncios, as retrações e evitações. Importa apenas relativamente se os estranhamentos experimentados sugerem a incidência de algo positivo ou negativo. Ali, muito provavelmente, estarão contidas, ou mesmo expressas, as teses que o emissor / a emissora defende.

Estarão contidas é o que se afirma aqui. Não necessariamente se apresentarão de forma explícita.

Mesmo quando não há o elemento aqui chamado de emoção em demasia, as teses que uma pessoa defende - sem que necessariamente ela queira e sem que necessariamente ela saiba - muito provavelmente estarão subliminarmente presentes em seus comunicados, em seus silêncios, em suas ações, em suas escolhas e decisões, em seus posicionamentos no mundo. A presença do elemento emocional é sintomática e mais facilmente perceptível. Mas, uma vez que essas teses costumam ser questões de honra, ou pressupostos dos quais a pessoa dificilmente se demove, elas permearão o conjunto de suas crenças e valores e poderão ser flagradas por quem quer que se disponha a examinar a peculiar coerência que alinhava esses posicionamentos.

São crenças, valores, ideias e concepções de homem, de vida e de mundo que permeiam a conduta, as atitudes e o comportamento de uma pessoa. Detalhando um pouco: são leituras que a pessoa faz da realidade, formas que ela tem de decodificar a realidade como um todo, ou alguns aspectos (para ela relevantes) da realidade e que, em razão do vulto que assumem para ela, passam a habitar seu acervo de verdades", suas formas de ver o mundo e as pessoas, a maneira como ela se vê e, mais importante do que tudo isso, norteiam-na, orientam-na, influenciam-na em suas escolhas, dão sustentação a suas ações, investimentos e empreendimentos na vida.

Alguns exemplos (simples, ou mesmo simplórios, mas representativos do que aqui se procura descrever):

'Minha mãe não gosta de mim.'

'Eu não tenho habilidade alguma para lidar com conflitos'

'Homens são todos iguais. Não se pode confiar neles'

'Tudo que ela quer é meu dinheiro. Ela não me vê como pessoa.' 
'Esse menino vai acabar me levando à loucura.'

'Eu espanto os homens e, então, eles me evitam ou se afastam de mim.' Em razão da perseverança e da estabilidade ao longo do tempo, isto é, em razão de a reflexão e a crítica disponíveis para a pessoa não darem conta de favorecer a revisão, ou mesmo a desconstrução de decodificações como essas, as crenças que inicialmente parecem meras teses acabam assumindo o caráter de leis implacáveis, irrevogáveis, coesas e fortemente estruturadas. São manifestações do que se conhece como rigidez, como gestalten fixas, como pressupostos tomados como inquestionáveis, ainda que muitas vezes sejam inconscientes.

De fato, nem sempre se pode dizer que essas teses sejam conscientes. Mesmo quando, pela observação do conjunto das ações e do discurso de alguém, o observador é levado a crer que a pessoa seja ciente de que esse suposto saber ocupa um lugar central na vida dela, o que se pode facilmente constatar, em especial em razão da experiência clínica, é que essas teses costumam ser inconscientes, ainda que tenham um poder de determinação descomunal.

que subjaz a isso é a seguinte dinâmica psíquica: o ser humano é norteado por leis alheias à sua vontade, ou seja, ainda que pareça conhecê-las muito bem e, ainda que, não deliberadamente, seja fiel e leal a elas, a influência que essas leis exercem não expressa uma função de sua consciência. Expressa, em lugar disso, motivações inconscientes, mesmo que inequivocamente regentes, determinantes, imperiosas ou imperativas. A lealdade a elas parece tamanha, que seria de se supor que elas fossem bastante conscientes e decorrentes ou derivadas de belos trabalhos de contato com a realidade e de captação confiável de seus meandros e de seus significados.

Mas, não. Não é isso o que acontece na maior parte das vezes.

Caso uma pessoa consiga verdadeiramente conscientizar a incidência de uma tese em seu repertório e, ainda assim, a tese permaneça viva e ativa após o necessário exame e verificação crítica, essa tese talvez evolua para mera constatação, boa percepção da realidade, e o conteúdo em questão pode se associar, se sistematizar, ou mesmo se coordenar com os demais conteúdos da consciência, com mérito para quem empreendeu esses esforços. Na maior parte das vezes, no entanto, o que se pode observar é outro fato, outro desenlace: o exame cauteloso, cuidadoso e rigoroso do conteúdo inconsciente, a constatação de que ele lá está e a admissão de, por muito tempo, ter sido refém dessa presença são fatores que permitem (aí, sim) a revisão daquela crença, a verificação de sua pertinência ou validade e, mesmo quando a decodificação original não chega a ser exatamente uma distorção grosseira da realidade, necessariamente a tese em questão perderá o caráter absoluto por ela assumido ao longo do tempo e será relativizada, ou seja, a exata medida dos fatos poderá ser alcançada. Vejamos: 
'Há algo em mim de que minha mãe de fato não gosta. Trata-se da facilidade que tenho em expressar sentimentos. Ela preferiria que eu me contivesse e fosse infinitamente mais discreta. Mas é disso, especificamente, que ela não gosta, uma vez que é o avesso do que ela exerce. Percebo, inclusive, que ao longo dos anos ela, de alguma maneira, parece ter-se habituado a isso, ou passado a ser mais acolhedora. Seus próprios sentimentos, portanto, já não precisam mais ficar reservados a sua íntima e silenciosa subjetividade.

'Eu me aflijo quando me vejo diante de um conflito. A ansiedade que se apresenta me avassala de tal forma que, num primeiro momento, eu me sinto diante de uma tarefa inabordável, grandiosa demais para minha restrita condição de manejar a dificuldade em questão. Preciso de tempo. Se eu aguardo até que me habitue um pouco à dificuldade, ou se eu dou tempo ao tempo para que a ansiedade se aplaque, eu me capacito a dar conta do conflito que está em jogo, mesmo que com dificuldade e algum vagar ou, ainda, com a ajuda de quem possa me liberar de minhas amarras, bloqueios, defesas e temores.'

Ou, quando for o caso, a revisão da tese à luz de um novo olhar depositado sobre os mesmos velhos fatos poderá dispensar a pessoa da condição de refém de uma crença (o suposto saber) e liberá-la para, se for relevante para ela, redirecionar sua energia vital e aplicá-la a outros fins, quem sabe a verificação de teses menos carregadas de emoção, melhor alinhadas ao campo das ciências, ou mesmo compatíveis com a vida anímica e capazes de leva-la à formulação de saberes mais confiáveis, sólidos e sustentáveis. Mesmo assim, se ela for uma pesquisadora bem instrumentada e adepta de métodos também confiáveis, ela verá que mesmo esses saberes mais sólidos poderão ser temporários e passíveis de constantes revisões.

O ato de saber é um empreendimento em constante movimento e transformação. $\bigcirc$ bom saber não adentra o campo da presunção e da cristalização, não se transforma em questão fechada.

grande risco que corre a pessoa que se apega a uma tese (ou a mais de uma, quando é o caso) está em que ela quase inevitavelmente irá comprovar sua tese, por assim dizer. Caminhará nessa direção e - perigo à vista! - pode ser bem sucedida. A comprovação da tese, no entanto, será fruto dos esforços que a pessoa faz para empregar todos os seus recursos no intento de se provar certa em suas percepções. Ela angariará inúmeros outros elementos da realidade e fará com que sejam evidências inequívocas de que suas suposições são dignas do status de fatos. Em razão desse risco, é bom que se alerte: cuidado com as teses levantadas, cuidado com as hipóteses defendidas, pois o crente fará com que elas sejam válidas e aceitáveis, ainda 
que, para tanto, persista em seu método e nele ocupe papel central a distorção da realidade.

Sim. Se conferirmos à palavra loucura o significado de aprisionamento a um estado de coisas idiossincrático e não compartilhado, sim. Mas, esse é um tipo de loucura ao qual nenhum ser humano fica imune. É uma loucura ampla e fartamente presente nas vidas das pessoas tidas como normais.

Alguns (talvez os mais comuns) agravantes para essa disfunção são os seguintes: o narcisismo e, dentro dessa dinâmica, em especial os traços mais marcantes do transtorno narcísico, a saber, a auto referência e a refratariedade a qualquer coisa, opinião, ponto de vista, conceito e perspectiva diferente da própria; a arrogância e a presunção; o egocentrismo; a adoção (sem crítica, sem filtro, sem avaliação) de referenciais alheios à saúde psíquica, em especial aquilo que se conhece como dogma.

Alguns contrapontos saudáveis para essa disfunção - e seus desdobramentos que, sim, podem ser irreversivelmente danosos e comprometedores, se não abordados com o devido cuidado - podem ser os seguintes: a reflexão; a abertura para seguir exercendo o olhar destinado a coisas e pessoas, bem como a si mesmo; o desenvolvimento da consciência crítica (palavra que, aqui, assume o significado contido na noção de ver, enxergar e tomar acordo de uma realidade tal como ela se apresenta, possuidora de conteúdos a ela inerentes e possíveis de serem captados com objetividade); humildade; abertura para o outro, para o diferente, para acolher perspectivas distintas das suas, capazes de ampliar seu campo de visão, isto é, um fluxo saudável no exercício da alteridade. Todos esses quesitos têm como mínimo denominador comum uma relação saudável no âmbito da polaridade consciência/inconsciente.

artigo que me dispus a redigir poderia ter aqui sua conclusão. No entanto, parece-me cabível rascunhar algumas (apenas algumas) interfaces entre o fenômeno descrito e algumas poucas noções teóricas da psicologia analítica junguiana e pós-junguiana. Com todo respeito pelas perspectivas de cada autor/pensador nessa abordagem, ou mesmo ciente das distinções entre as diferentes perspectivas no escopo da psicologia analítica (clássica, desenvolvimentista, arquetípica), opto por dar voz a minhas próprias ideias ou à leitura que faço das ideias dos diversos autores, com suas adesões às especificidades de cada escola. Não vejo entre elas as incompatibilidades que se divulgam em publicações, então me permito conciliá-las na leitura que faço de fenômenos psíquicos. Para os propósitos deste artigo, esse esforço de conciliação pode não honrar cada escola tomada separadamente, mas contemplará as luzes fabulosas que cada uma delas fez incidir sobre os meandros da psique. 
Como no bojo do fenômeno descrito encontra-se uma decodificação particular da realidade, uma leitura peculiar, uma captação a partir de um único ângulo e, sob os auspícios dele, uma distorção da realidade, cabe aqui um breve comentário sobre a noção de projeção. Corriqueiro no linguajar da psicologia, o termo, tal como o emprego aqui, especificamente, sintetiza uma situação que talvez se possa caracterizar com palavras simples e fáceis de compreender. A pessoa percebe que percebe (um objeto, uma situação, um percepto qualquer), mas não percebe que projeta ao perceber. Supõe, portanto, que a captação que obtém fotografa e radiografa de forma confiável o objeto examinado, sem se dar conta de que ela sobrepõe ao objeto conteúdos que a ele não pertencem, mas são atributos de sua própria subjetividade.

O objeto é o receptáculo da projeção, a tela. Mas, o conteúdo projetado não pertence ao objeto, sim à interioridade do examinador. Ainda que o objeto seja uma tela aparentemente apropriada para acolher a projeção, ou seja, ainda que a projeção não seja massiva, isto é, em nada honre os conteúdos inerentes à tela, a decodificação que dele se faz não é isenta da contaminação por parte da subjetividade do observador. Daí a pessoa imaginar que apenas percebe, quando talvez ela sobreponha ao que percebe um conteúdo, um colorido e um significado que não são inerentes ao objeto, mas que ela o compele a deles ser depositário.

A teoria dos complexos inclui noções que, em parte, podem favorecer o exame de alguns elementos do fenômeno descrito. Vejamos: a tese defendida pela pessoa abrange conteúdos psíquicos que se organizam em torno de um núcleo carregado de afeto, segundo as ideias de Jung (1959/2016). Conteúdos assemelhados, aparentados e compatíveis com esses, os nucleares, agregamse ao mesmo núcleo e fortalecem o conglomerado que assim se forma, chegando ao ponto de configurar uma espécie de subpersonalidade inconsciente.

De fato, observando-se cuidadosamente as inúmeras manifestações de um complexo assim formado, ter-se-á a impressão de que habita o interior da pessoa um (ou alguns) ser(es) monotemático(s), um personagem caracterizado por um pensamento diretor, ou por uma pseudopercepção, por mais obsessiva que seja, ou, ainda, um sentimento que se descolou da realidade que talvez um dia tenha the dado origem, mas que se firmou como um conteúdo inconsciente autônomo e dissociado do ambiente atual. Quando sob os auspícios das crenças, valores, supostas decodificações e sentimentos alinhados ao complexo, a pessoa (sem que necessariamente queira e sem que saiba) deixa-se tomar pelo complexo, que utiliza recursos tradicionalmente reconhecidos como egoicos para se expressar, sem que ali se possa divisar um ego - exceto, claro, um ego apossado pelo complexo, talvez com ele identificado. 
Em situações dessa ordem, o que se observa guarda um traço de estereotipia, de caricatura, algo difícil de se abordar pela via dialógica e pelos esforços reflexivos no campo da interpessoalidade, principalmente no plano das relações corriqueiras da vida da pessoa. As teses aqui referidas não podem ser tomadas como características de um complexo. De maneira alguma. Nem todo complexo inclui teses. Mas, no âmbito de qualquer complexo inconsciente, o conglomerado que se forma pode assumir a fenomenologia de uma tese, assim como pode assumir um número infinito de outros formatos. Mesmo quando se considera que, ainda que não sejam tecnicamente terapêuticas, algumas relações interpessoais podem ter decorrências terapêuticas, isto é, podem ser promotoras de mudanças e de evolução psíquica, engendrando maturidade e discernimento, o trabalho terapêutico propriamente dito é o que se apresenta como suficientemente instrumentado (justamente em razão de seus quesitos técnicos) para promover a dissolução de um complexo. Nada garante que a consecução desse objetivo se viabilize ou se efetive.

Aplica-se à noção de complexo o mesmo que se aplica a tudo que se tome como sendo da ordem do inconsciente, ou seja, há de se contemplar a inexorável parcela de inconsciente não conscientizável, incognoscível, o que, aliás, não indica que o destino humano seja ruim, pouco saudável, ou mesmo empobrecido. Mas os esforços na direção da realização do intento da própria psique - ou seja, a integração psíquica - haverão de ser empreendidos dentro dos limites de cada pessoa e de cada profissional que a assiste.

Para Edinger (1971), um dos possíveis significados da operação alquímica da solutio está nisto: uma espécie de regresso às matrizes psíquicas a serviço da progressão da libido. Quando submetida à solutio, a psique visita seus alicerces equivalentes ao ambiente amniótico e, com isso, restaura o contato com a libido em sua matriz. A retomada do processo evolutivo (justamente o propósito da solutio) não é garantia de que esse movimento resulte numa íntegra e definitiva coagulatio, mas terá tido o imenso valor de relativamente dissolver as amarras que mantêm coeso o conglomerado complexo.

A superação das dificuldades alicerçadas num complexo requer, então, o que se convencionou chamar de dissolução do complexo. É necessária muita água para que um cristal se dissolva. E, uma vez que é alta a probabilidade de que a gênese do complexo tenha sido um fenômeno relacional, quem sabe ligado aos primórdios de uma vida, ou à incidência de um trauma não elaborado, há de se contemplar a noção de que um novo palco relacional se preste à reconfiguração do campo de significados e, consequentemente, contribua para a dissolução do complexo. Claro está que, embora não de todo impossível, é rara a obtenção desse tipo de superação nas relações interpessoais cotidianas, por mais especiais e significativas que sejam. 
Na grande maioria das oportunidades a dissolução de um complexo requer um manejo técnico (aqui talvez se possa contemplar o uso instrumental da contratransferência). É para isso (dentre outros desafios, claro) que um psicoterapeuta é treinado e qualificado. A água que dissolve o complexo brota da coniunctio Eros/Logos alcançada e sustentada instrumentalmente por um psicoterapeuta bem treinado. $\bigcirc$ Eros dá conta dos fatores relacionais, que se reinventam na concretude do encontro analítico com tudo que esse encontro tem de novo, inusitado e imprevisto, porém fortemente almejado pelo analisando. $\bigcirc$ Logos, por sua vez, dá conta de oferecer um vaso continente para que o líquido relacional não se perca e para que a função reflexiva, não raro ausente numa pessoa com as características aqui descritas, se restaure ou se inaugure.

Um fator facilitador para o bem-suceder do processo é o conhecimento do qual o psicoterapeuta de orientação junguiana dispõe, segundo o qual todo complexo está necessariamente enraizado num território arquetípico (o que, obviamente, se aplica a todo e qualquer conteúdo psíquico). Esse saber capacita o psicoterapeuta a identificar no âmago do complexo o intento legítimo da alma. Embora legítimo, esse intento não pôde ainda ser alcançado, uma vez que a constelação arquetípica disponível para o analisando, no âmbito das idiossincrasias de sua vida, não honrou o cerne da questão. Sabiamente, no entanto, esse cerne (o desejo da alma) não se extingue, ainda que ele se restrinja a se apresentar com o viés de uma história de vida comprometedora e promotora de distorções. $\bigcirc$ trabalho do psicoterapeuta, então, consistirá em localizar o desejo da alma contido na tese que a pessoa defende, em especial de modo a explicitá-lo e validá-lo.

○ que não se pode validar é a forma como aquele desejo vem sendo abordado ao longo da vida. Porém, localizado o âmago do desejo, há de se poder pesquisar uma forma autêntica, ética, saudável e sábia de admitir o desejo, reconhecê-lo, e, se possível, se ao alcance da pessoa e se cabível no plano da ética nas relações, também realizá-lo. Mas, uma coisa não se pode subestimar: o reconhecimento de um desejo afirma uma pessoa, sua identidade, o projeto de vir a ser quem ela é, no plano da individuação. A realização do desejo, nem sempre. É necessário que se examine esse quesito com vagar, calma e critério.

Não necessariamente, mas com frequência, o âmbito das motivações na vida de uma pessoa pode ser flagrado nas disposições alcançadas pela função inferior, no espectro tipológico da personalidade. Isso, parece-me, aplica-se em especial à função inferior dos introvertidos, que são extrovertidas. Como os introvertidos estão referenciados prioritariamente em elementos colhidos em sua subjetividade, a inferioridade da função extrovertida, oposta à função inferior, é contemplada como tendo grande valor e, não raro, é dela que vêm as motivações (na maior parte das vezes inconscientes, ou apenas 
relativamente conscientes) para suas ações, decisões e posicionamentos. Assim, por exemplo, a vida de um intuitivo introvertido pode ser uma ode à sensorialidade extrovertida, tida e vista por ele como admirável.

Muitas teses podem ser vistas à luz desse quesito. Apenas a título de exemplo, lembro-me de ter analisado uma mulher sensorial introvertida, cuja tese consistia em uma proposta de tratamento de saúde para a humanidade. Ela concebia essa proposição de forma detalhada, minuciosamente descrita, apaixonadamente defendida em suas finalidades e propósitos. Porém, faltavaThe o ímpeto corajoso e ousado da intuição extrovertida para fazer valer seu intento no mundo, operacionalmente. Ela dispunha de uma noção de metodologia, mas não vinha em seu socorro a disposição para colocar em movimento as ações que inseririam sua metodologia no campo da ciência, sequer, ou da implantação de sua abordagem no âmbito do tratamento à saúde. Em lugar disso, deixava-se impactar profundamente pelo significado e pela beleza de sua proposição, como é de se esperar da parte de um sensorial introvertido. Ela secretamente sonhava com a imagem de um intuitivo extrovertido que se apaixonaria por sua ideia e não hesitaria em fazê-la valer. Feita essa breve e paupérrima perambulação pelos crivos teóricos, retomemos um dos exemplos lançados no início do texto. Uma análise do exemplo poderá agregar a esta varredura mais alguns elementos de teoria quiçá úteis para o exame no fenômeno aqui focalizado.

Claro que há mulheres que pensam assim e deixam transparecer com a devida clareza sua avaliação dos homens. Mas é maior o número de mulheres que têm essa crença como uma espécie de pressuposto inconsciente, sem que a questionem e sem que sequer a formulem com palavras tão certeiras. A observação do comportamento, das atitudes e posicionamentos da mulher, porém, permitem ao observador deduzir que, pelo que tudo indica, essa tese permeia sua conduta na vida, bem como delineia o lugar que o elemento masculino ocupará em sua vida, assim como o lugar que ela atribuirá a si mesma nas parcerias com homens.

Para as avaliações de Jung, as manifestações de animus em sua versão negativa costumam incluir elementos dessa ordem: generalizações, pressupostos inconscientes e inquestionados, bem como a formulação de teorias a respeito de facetas da vida, dos seres humanos, do mundo e, não menos importantes, teorias a respeito da própria pessoa, sem que se possam qualificar como parcelas de autoconhecimento. Não raro, a mulher que pressupõe ser o homem (cada homem, todo homem) não confiável costuma ter de si mesma a visão de um ser confiável, mas também a noção de ser vítima (potencial ou concretamente) da não confiabilidade de seus pares masculinos, tomados necessariamente como algozes. 
Com análoga frequência, a mulher prisioneira dessa visão é também cativa de um conceito de feminino inferiorizado, quando visto em contraste com o conceito de masculino. Nesse caso, conferir ao homem um status de não confiabilidade equivaleria a experimentar um ressentimento (para com a cultura, para com o cânon coletivo, do qual o homem seria um porta-voz) por ser vista e tida como detentora de uma inferioridade supostamente inerente a seu gênero, algo que, se examinado à luz das bases arquetípicas do feminino, a alma feminina sabiamente não tolera admitir.

A superação das dificuldades contidas nesse repertório requererá o exame minucioso de fatores externos e internos. Externamente, o que, exatamente, está contido no imaginário coletivo - histórica e socialmente construído compelindo a mulher a perceber a si mesma e ao outro de forma distorcida? Uma vez localizado e diferenciado esse acervo de conteúdos e esse gabarito delimitador das especificidades de gênero e de seu valor no plano coletivo, o trabalho requerido é o de adesão à perspectiva da individuação, ou seja, a tarefa de desvencilhar-se, de desenredar-se das amarras do coletivo ao qual a mulher pertence, imunizando-se quanto a seus venenos e fortalecendo-se no plano do automorfismo.

Automorfismo e adaptabilidade formam uma polaridade relevante. Sim, a noção de pertença e, com ela, os esforços adaptativos têm grande relevância, mas está ao alcance de todos os seres humanos o desenvolvimento de recursos transformadores para que o mundo circundante também se adeque à realidade das pessoas que o habitam. O automorfismo, por sua vez, contempla aquilo que é próprio de cada ser humano e que precisa ser honrado - se não pelo mundo, então pela própria pessoa. Para que isso seja alcançado, é necessário que se faça um exame minucioso e respeitoso dos conteúdos internos e de suas bases arquetípicas, que a eles confere legitimidade. $\bigcirc$ processo de humanização se insere na intersecção entre adaptabilidade e automorfismo, ou seja, no encontro entre externo e interno e sua difícil - porém possível - interlocução.

A psique tem suas próprias teses. A tarefa de cada ser humano é compatibilizar - ou, pelo menos, caminhar no sentido de compatibilizar - seu modo próprio de ser e o Desejo (com D maiúsculo, ou seja, uma função do Self) da psique. As teses meramente egoicas, defensivas e encharcadas de temores - mas também esperanças - não aprisionarão uma pessoa, onde e quando ela for capaz de empreender a correta escuta dos desígnios de sua alma. Belo desafio a se acolher! 


\section{Referências}

Edinger, E. F. (1971). Jung. In Anatomia da psique: o simbolismo alquímico na psicoterapia (p. 11-106). São Paulo: Cultrix.

Jung, C. G. (2016). A Natureza da Psique (O.C., Vol. VIII/2). Petrópolis, RJ: Vozes. (Trabalho original publicado em 1959).

Minicurrículo: Alberto Pereira Lima Filho - Mestre em Psicologia Clínica pela Universidade de São Paulo - USP. Doutor em Psicologia Clínica pela Pontifícia Universidade Católica - PUC-SP. Escritor e músico. Diretor da Opus Psicologia e Educação Ltda.E-mail: albertoplima@terra.com.br 